DOI: https://doi.org/10.11144/Javeriana.upsy16-5.casv

\title{
Choque y adaptación sociocultural una visión en espejo: vascos y brasileños
}

\section{Clash and socio-cultural adaptation. A mirror image: Basques and Brazilians}

Recepción: 24 Mayo 2017 | Aprobación: 28 Agosto 2017

\author{
Sonia Gení Padoan Ribeiro De Luca ${ }^{\mathrm{a}}$ \\ Universidad del País Vasco, España \\ ORCID: http://orcid.org/0000-0001-6289-647X \\ SaioA TElletXeA \\ Universidad del País Vasco, España
}

\footnotetext{
a Autor de correspondencia. Correo electrónico: soniagrdeluca@hotmail.com

Para citar este artículo: De Luca, Sonia, \& Telletxea, S. (2017). Choque y adaptación sociocultural una visión en espejo: vascos y brasileños. Universitas Psychologica, 16(5), 1-14. https://doi.org/10.11144/ Javeriana.upsy 16-5.casv
}

\begin{abstract}
RESUMEN
Los inmigrantes experimentan cambios en las relaciones interpersonales y comunicativas, así como en el manejo de la distancia social. Este estudio analiza dichos cambios en dos grupos y contextos culturales: los inmigrantes brasileños en el País Vasco y los inmigrantes vascos en Brasil. Se esperan diferencias en las dimensiones del ajuste sociocultural en función del tiempo de estancia y del grupo, así como en las prácticas culturales del país de origen y de acogida. El estudio es transversal y retrospectivo. Los resultados muestran altas dificultades durante el primer año, en donde predominan las relativas al manejo de las Relaciones interpersonales, y posteriormente adquiere más importancia la dimensión de Manejo de la distancia social, especialmente en el caso de los vascos.

Palabras clave

choque cultural; ajuste sociocultural; inmigración.
\end{abstract}

\section{ABSTRACT}

Immigrants experience changes in their interpersonal and communicative relationships, so as to deal with social distance. This study analyzes such changes among two different groups and cultural contexts: Brazilian immigrants in the Basque Country, and Basque immigrants in Brazil. Differences are expected in the dimensions of socio-cultural adjustment due to the time spent in the stay, the group, and also to cultural practices of the origin and host country. The study is transversal and retrospective. Results show that during the first year, difficulties are pronounced with a predominance of Interpersonal Relationships-related ones and subsequently, a higher importance of the dimension Social Distance Management, specifically among the Basque.

Keywords

cultural clash; socio-cultural adjustment; immigration.

España es un país caracterizado por diversos ciclos migratorios, tanto de emigración como de inmigración. Por una parte, la salida de españoles con destino a otros países ha sido numerosa hasta los años setenta, a partir de allí ocurre un 
periodo de estancamiento y vuelve a intensificarse a principio de este siglo (Gives, 2013). La entrada de inmigrantes en España, que durante décadas fue gradual, se acentúa a finales siglo XX y principios del XXI.

Por otra parte, a partir de los años ochenta Brasil pasa de ser un país principalmente receptor de emigrantes, a ser un país emisor de inmigrantes, hecho que ha ido aumentando a lo largo de estos últimos años.

La inmigración brasileña en España empieza a adquirir fuerza la última década del siglo XX, principalmente impulsada por motivos materialistas (Masanet \& Padilla, 2010), mientras que la inmigración de españoles a Brasil presenta un ascenso notable a partir del 2008, potenciada por el inicio de la crisis económica española.

Investigaciones realizadas por órganos oficiales, tanto en España como en Brasil, indican que los dos países ocupan el quinto puesto en la preferencia de destino extranjero de los emigrantes. En España actualmente residen cerca de 119000 inmigrantes brasileños, y en Brasil, cerca de 117523 inmigrantes españoles (PERE, 2014; Ministério das Relações Exteriores do Brasil, 2013).

\section{Dificultades de adaptación}

El ajuste o adaptación a una nueva cultura implica fundamentalmente tres aspectos: a) la adaptación psicológica, concebida para mantener una buena balanza de afectos, satisfacción con el nuevo medio cultural y su aceptación; b) el aprendizaje cultural, la adquisición de las habilidades sociales que permiten manejarse en la nueva cultura y tener buenas relaciones con las personas de la sociedad de acogida, y c) la realización de las conductas adecuadas para la resolución exitosa de las tareas sociales (Moghaddam, Taylor, \& Wrigth, 1993). A partir de estos aspectos, Bochner (2003) ha propuesto un modelo de contacto cultural denominado ABC (Affect, Behavior, Cognition), donde por una parte (A) representa el aspecto afectivo y corresponde a los principales indicadores de la adaptación psicológica, por otra parte (B) y (C) representan respectivamente los aspectos cognitivo y conductual, y corresponden a la adaptación sociocultural. La adaptación psicológica y sociocultural al nuevo contexto están relacionadas entre sí, aunque presenten cierta autonomía, manifestando diversos patrones de evolución temporal y siendo explicadas por distintos factores psicosociales (Chun, Organista, \& Marín, 2003; de Luca, Bobowik, \& Basabe, 2011; Smith \& Bond, 1999; Ward, Bochner, \& Furnham, 2001).

\section{Dificultades de adaptación sociocultural}

La adaptación sociocultural concebida como un proceso de aprendizaje social, se refiere a la aplicación de las habilidades sociales, disposición y la capacidad para integrarse de manera positiva y para manejar los diferentes aspectos de la nueva cultura. Esta adaptación se evalúa a través de las dificultades sociales, y se asocia positivamente al tiempo de residencia, a una buena capacidad lingüística, a las estrategias de aculturación, a un alto contacto con los autóctonos, a una menor distancia cultural y a un mayor conocimiento cultural (Ward \& Kennedy, 1999; Zlobina, Basabe, \& Páez, 2004). Resultados obtenidos a través de estudios realizados, tanto en esta cultura como en diversos contextos culturales, confirman la existencia de factores predictores de la adaptación sociocultural universalmente compartidos, como el tiempo de residencia, la discriminación percibida y el estatus de inmigrante (legalidad de residencia), el contacto con autóctonos, el apoyo recibido de su parte, la distancia cultural percibida y la educación (de Luca et al., 2011; Zlobina et al., 2004).

Retomando el modelo de adaptación sociocultural $\mathrm{ABC}$, propuesto por Bochner (2003), en el cual B y C corresponden respectivamente a los aspectos conductuales y cognitivos, los autores Ward y Kennedy (1999), en sus estudios hallaron la existencia de una estructura bidimensional formada por un factor cognitivo y otro conductual. Estos autores denominaron "Empatía Cultural y 
Relacionalidad" al aspecto cognitivo y "Esfuerzos y Riesgos Impersonales" al aspecto conductual. Esta estructura bidimensional ha sido objeto de investigación en un estudio previo (de Luca et al., 2011), en el que se constatan las dos dimensiones, la primera cognitiva, denominada "Aprendizaje cultural y comunicación" (ACC), que por una parte explora aspectos relativos a acostumbrarse al ritmo de vida, a la comida, al clima, a comprender el punto de vista de la cultura local, a practicar sus creencias religiosas o a vivir lejos de la familia, y por otra parte se vincula con la comunicación en situaciones como: hacerse entender, ir de compras, entender las bromas, entender el acento local, hacer amigos e ir al médico. Mientras que la segunda dimensión, la conductual, denominada como "Manejo de la distancia social" (MDS), vinculada al manejo de la jerarquía y de las relaciones interpersonales engloba aspectos como: tratar con personas de mayor estatus, relacionarse con personas de otro sexo, tratar con los que miran fijamente, ser entrevistado, tratar con alguien desagradable o conocer a personas desconocidas.

En relación con la influencia del tiempo de estancia en la adaptación sociocultural, inicialmente fue sugerido que ocurría de forma lineal, de modo que mejoraba el bienestar subjetivo conforme aumentaba el tiempo de residencia en la sociedad de acogida, debido a la posibilidad de un mayor contacto e identificación con los autóctonos y con su cultura (LaFromboise, Coleman, \& Gerton, 1993). Posteriormente se propuso un modelo curvilíneo, en "U", que indicaba una trayectoria en tres momentos; un primero correspondiente al inicio, en el cual la adaptación tiende a ser mayor debido al estímulo y el entusiasmo provocados por la novedad de la nueva cultura; un segundo, cuando se instala una rutina y la adaptación tiende a disminuir porque los inmigrantes se percatan de las limitaciones existentes, como la dificultad para dominar el idioma, o de las dificultades de interacción con los autóctonos; $\mathrm{y}$ un tercero, cuando pasa el tiempo y la persona acepta y aprende las costumbres y valores de la sociedad de acogida, reúne condiciones para afrontarla y ser uno más, donde se apreciaría una ligera mejoría (Moghaddam et al., 1993; Sabatier \& Berry, 1996). Sin embargo, existe un cuestionamiento en torno a este modelo curvilíneo, en el sentido de que generalmente la fase de asentamiento migratorio suele acompañarse de afectividad negativa, y lentamente se va produciendo una adaptación al nuevo medio (Ward, 1996; Ward et al., 2001). En el contexto vasco (Basabe, Páez, Aierdi, \& Jiménez-Aristizabal, 2009), con inmigrantes de diversas nacionalidades, se comprobó que conforme aumentaba el tiempo de residencia en el país de acogida, disminuía la afectividad negativa. En otro estudio (de Luca et al., 2011) en el País Vasco, con inmigrantes brasileños, se comprobó que disminuyeron los niveles de dificultad sociocultural conforme aumentaba el tiempo de estancia; los efectos se presentaron con mayor intensidad en la dimensión de "Aprendizaje cultural y comunicación" (ACC), que en la dimensión de "Manejo de la distancia social" (MDS). En la primera dimensión (ACC), las diferencias fueron mayores para los ítems relacionados con la comunicación y con acostumbrarse a una nueva cultura; en la segunda dimensión (MDS), las diferencias de mayor tamaño se vincularon a las situaciones estresantes y que requieren adaptación a las normas sociales deseadas en el nuevo contexto cultural. Las diferencias fueron menores en el caso de aspectos tales como hacer amigos autóctonos o acudir a lugares religiosos (ACC), o tratar con personas que miran fijamente $y$ de mayor estatus (MDS). Estudios realizados en otros contextos culturales, también confirmaron que las mayores dificultades de adaptación sociocultural suelen ocurrir al comienzo de la estancia en el país de acogida, cuando los problemas se presentan de manera más intensa (Ward \& Kennedy, 1999).

\section{Objetivos e hipótesis}

Este estudio buscó contrastar las similitudes y diferencias en la adaptación sociocultural de dos grupos migrantes cuyo estatus social y contexto cultural de recepción son divergentes. 
Se evidenció cómo un grupo de brasileños se adapta al contexto del País Vasco y, en espejo, cómo un grupo de vascos se adapta al contexto de Brasil.

Hip.1. Las dificultades de adaptación Sociocultural (SCAS) serán más altas durante el primer año y disminuirán con los años de estancia en el país de acogida (Basabe et al., 2009; de Luca et al., 2011; LaFromboise et al., 1993; Ward \& Kennedy, 1999).

Hip.2. Las diferencias entre los grupos migrantes vasco y brasileño serán mayores en la dimensión relacionada con el Manejo de la Distancia Social y las relaciones jerárquicas. Estas diferencias afectarán a cuestiones como: tratar con personas de mayor estatus, relacionarse con personas de otro sexo, tratar con los que miran fijamente, ser entrevistado, tratar con alguien desagradable, conocer a personas desconocidas. También son esperables diferencias en torno a aspectos como acostumbrarse al ritmo de vida (más rápido en el País Vasco), a la comida (aspecto más relevante para identidad social vasca), o al clima (más central para la cultura brasileña). Sin embargo, otros aspectos serán igualmente importantes en ambos colectivos, como comprender el sentido del humor, el punto de vista de la cultura local, practicar sus creencias religiosas, o vivir lejos de la familia.

Hip.3. Ambos grupos inmigrantes presentarán una rápida adaptación, de manera que asimilarán las prácticas culturales de la sociedad de acogida al tiempo que se mantendrán las prácticas de origen. Sin embargo, el tiempo de estancia marcará diferencias de aculturación entre los vascos y brasileños en la adopción de la cultura de acogida y la manutención de la cultura de origen (Zlobina et al., 2004).

\section{Método}

Se crearon dos grupos apareados en edad y sexo de inmigrantes vascos en Brasil y brasileños en el País Vasco, ambos grupos procedían (brasileños) o residían (vascos) en la misma región de Brasil (São Paulo). Para la selección de los grupos, se tomaron dos muestras, una de brasileños entrevistados en España $(N=100)$ (de Luca et al., 2011). La otra, estaba compuesta por vascos $(N=67)$ entrevistados en Brasil. Al crear grupos equiparados, la muestra tuvo que reducirse a $47 / 47$, para ello primero se restringió la muestra de vascos, puesto que entre ellos había personas con muy larga estancia en Brasil, que habían emigrado en los años cincuenta (1950), y con edades muy avanzadas (más de 64 años). Sin embargo, los brasileños emigrados eran más jóvenes y emigraron a partir de los años noventa (1990). Por ello, se seleccionaron personas de menos de 64 años, se dividió la muestra por tiempo de estancia (más o menos de 121 meses), y se seleccionaron para cada participante vasco, sus equivalentes brasileños en edad y sexo. Después de esto, se seleccionó aquel participante (hombre/mujer y grupo de edad) que compartiera el mismo estado civil y nivel educativo. Finalmente, se consiguió equiparar 47 participantes por grupo.

\section{Muestra}

Participaron 94 inmigrantes, 47 procedentes del País Vasco y residentes en la provincia de São Paulo de Brasil, y 47 de Brasil y residentes en la provincia de Álava, en el País Vasco. Los participantes brasileños y sus familiares en su mayoría eran trabajadores técnicos del sector de la aeronáutica, que salieron de Brasil con contrato de trabajo y permiso de residencia establecidos en origen, asimismo los familiares que no gozaron de tales beneficios inmigraron posteriormente por reagrupación familiar. Los inmigrantes vascos eran trabajadores técnicos en diversas áreas, que salieron de España con un contrato temporal para realizar un trabajo específico y decidieron quedarse, y los que contrajeron matrimonio con personas brasileñas (véase Tabla 1). 
TABLA 1

Características sociodemográficas de muestras divididas: Grupo 1 y Grupo 2

\begin{tabular}{|c|c|c|c|}
\hline & & Grupo 1 & Grupo 2 \\
\hline \multicolumn{2}{|c|}{ Edad M (SD) } & $\begin{array}{c}43.11 \\
(12.08)\end{array}$ & $\begin{array}{r}42.4 \\
(12.41)\end{array}$ \\
\hline \multicolumn{2}{|c|}{$\begin{array}{l}\text { Tiempo de estancia o residencia } \\
\text { en meses } M(D T)\end{array}$} & $\begin{array}{c}190.85 \\
(173.28)\end{array}$ & $\begin{array}{r}149.4 \\
(53.36) \\
\end{array}$ \\
\hline \multicolumn{2}{|c|}{ Sexo (femenino) } & $44.7 \%$ & $44.7 \%$ \\
\hline \multirow{2}{*}{\multicolumn{2}{|c|}{$\begin{array}{l}\text { Vivir con pareja } \\
\text { Pareja nacida en el país de } \\
\text { acogida }\end{array}$}} & $63.8 \%$ & $68.1 \%$ \\
\hline & & $23.4 \%$ & $55.3 \%$ \\
\hline \multicolumn{2}{|c|}{ Uno o más hijos } & $67.4 \%$ & $66 \%$ \\
\hline \multirow[t]{3}{*}{$\begin{array}{l}\text { Educación } \\
\text { completa }\end{array}$} & $\begin{array}{l}\text { Educación } \\
\text { secundaria }\end{array}$ & $42.6 \%$ & $38.3 \%$ \\
\hline & $\begin{array}{l}\text { Universitaria } \\
\text { incompleta }\end{array}$ & $8.5 \%$ & $36.2 \%$ \\
\hline & $\begin{array}{l}\text { Universitaria } \\
\text { completa }\end{array}$ & $48.9 \%$ & $25.5 \%$ \\
\hline \multirow[t]{5}{*}{$\begin{array}{l}\text { Situación } \\
\text { laboral }\end{array}$} & $\begin{array}{l}\text { Profesionalmente } \\
\text { activos }\end{array}$ & $74.5 \%$ & $95.7 \%$ \\
\hline & Desempleados & $4.3 \%$ & $0 \%$ \\
\hline & Jubilados & $2.1 \%$ & $2.1 \%$ \\
\hline & Amas de casa & $10.6 \%$ & $2.1 \%$ \\
\hline & Estudiantes & $8.5 \%$ & $0 \%$ \\
\hline \multirow[t]{2}{*}{$\begin{array}{l}\text { Situación } \\
\text { legal }\end{array}$} & $\begin{array}{l}\text { Con un permiso de } \\
\text { residencia }\end{array}$ & $85.1 \%$ & $25.5 \%$ \\
\hline & $\begin{array}{l}\text { Naturalizados/Naci } \\
\text { onalizados }\end{array}$ & $14.9 \%$ & $74.5 \%$ \\
\hline \multicolumn{4}{|c|}{$\begin{array}{c}\text { Grupo } 1=\text { Inmigrantes vascos } \\
\text { y Grupo } 2=\text { Inmigrantes } \\
\text { Fuente: elaboración propia. }\end{array}$} \\
\hline
\end{tabular}

\section{Procedimiento}

Los brasileños residentes en el País Vasco fueron reclutados por medio de los contactos con asociaciones culturales y redes sociales. En Brasil se contó con el apoyo de la Asociación vasca "Eusko Alkartasuna" de São Paulo. Todos los participantes fueron voluntarios. Se informo de los objetivos de esta, y se tuvo un consentimiento preparado siguiendo el protocolo del Consejo de Ética de la UPVEHU. Todos fueron anonimizados.

\section{Variables e indicadores}

Escala de adaptación socio cultural - SCAS (de Luca et al., 2011; Furnham \& Bochner, 1982; Ward \& Kennedy, 1999). Se solicitaba indicar "el grado de dificultad que sintió en situaciones como hacerse entender, ir de compras, relacionarse con personas del otro sexo y tratar con personas de mayor edad", con un formato de respuesta de 1 (ninguna) a 5 (extrema). Compuesta por diecinueve ítems y dos dimensiones, la primera relativa a las Relaciones Interpersonales y Comunicación; y la otra, relativa al Manejo de la Distancia Social y Jerarquía (véase tabla 2). Se aplicó la escala en relación con dos momentos temporales: 1) primer año de residencia en el país de acogida (retrospectiva), y 2) en el momento actual (cuando se realizó la entrevista). Los índices de fiabilidad oscilaron entre $\alpha=0.94$ y $\alpha=0.87$.

\section{Escalas de Aculturación}

Escala de Prácticas culturales (Basabe et al., 2009). Consta de cinco ítems (e.g., "Consume comida y bebida" del país de origen/país de acogida) y la lealtad lingüística ("Habla español/ vasco/portugués”), con rango de respuestas entre 1 (nada) a 5 (mucho). Los coeficientes de fiabilidad para las conductas del país de origen en vascos fueron $\alpha=0.64$ y en brasileños, $\alpha=0.75$, y para el país de acogida, en vascos y brasileños $\alpha=0.61$ respectivamente.

Escala de Actitudes de Aculturación (Navas et al., 2004). Consta de cuatro ítems, referidos al deseo de mantener las costumbres de la sociedad de origen y de adoptar las costumbres de la sociedad de acogida, en las esferas privada (la familia, las amistades, las creencias y costumbres religiosas), y en la esfera pública (trabajo), con rango de respuesta de 1 (nada) a 5 (mucho). La consistencia interna fue $\alpha=0.79$ y $\alpha=0.66$ para los países de origen y acogida.

\section{Análisis de Datos}

Se aplicaron análisis de varianza para contrastar las diferencias entre inmigrantes vascos $y$ brasileños en las variables en estudio, los efectos principales del grupo y tiempos de estancia (menos y más de siete años), y efectos de interacción grupo por tiempo. Se estableció un 
nivel de error de $\mathrm{p} \leq 0.05$ para todos los análisis, que se realizaron por medio del programa SPSSversión 22.

\section{Resultados}

Dificultades durante el $1^{o}$ año de estancia y el momento actual

Considerando las puntuaciones globales de SCAS (media del conjunto de ítems y por sub-dimensiones), el primer año de estancia el choque fue mayor que con posterioridad, así las puntuaciones se situaron alrededor de 3 en una escala de 1 a 5 en el primer año, y posteriormente las puntuaciones fueron menores de 2 tanto entre los vascos como entre los brasileños (véase Tabla 2) (Hip.1).

Para los grupos de inmigrantes vascos y brasileños de forma conjunta las dificultades fueron altas y aquellos aspectos que obtuvieron mayores puntuaciones ( $>3$ ) fueron los siguientes: entender el sentido del humor $(\mathrm{M}=$ $3.8, \mathrm{DT}=0.97)$, vivir lejos de la familia $(\mathrm{M}=$ $3.59, \mathrm{DT}=1.28)$, entender el idioma y el acento local $(M=3.54, D T=1.07)$, comprender el punto de vista de la cultura local $(\mathrm{M}=3.5$, DT $=1.08)$, tratar con la burocracia $(M=3.5$, $D T=1.1)$, hacerse entender $(M=3.4, D T=$ $1.18)$, afrontar el clima $(M=3.26, D T=1.5)$, acostumbrarse a la comida del lugar $(M=3.24$, $D T=1.25)$, acostumbrarse al ritmo de vida $(M$ $=3.23, \mathrm{DT}=1.37)$, hacer amigos nativos $(\mathrm{M}=$ $3.17, D T=1.15)$, ser entrevistado $(M=3.11$, $D T=1.24)$, conocer a desconocidos $(M=3.07$, DT $=1.05)$, y tratar con personas desagradables $(\mathrm{M}=3.03, \mathrm{DT}=1.15)$. Aquellos aspectos en los que hubo menores puntuaciones $(<3)$ fueron los siguientes: ir al médico $(M=2.77, D T=1.22)$, tratar con personas que miran fijamente $(\mathrm{M}=$ $2.76, D T=1.04)$, ir de compras $(M=2.43, D T$ $=1.15)$, relacionarse con personas de otro sexo $(\mathrm{M}=2.4, \mathrm{DT}=1.2)$, tratar con personas de mayor edad $(\mathrm{M}=2.3, \mathrm{DT}=0.91)$ y acudir a lugares de práctica religiosa $(M=2.27, D T=$ 1.26).
Choque cultural: Relaciones interpersonales y comunicación: diferencias vascos y brasileños

Durante el "primer año de estancia" (medida retrospectiva), los brasileños reportan más dificultades interpersonales y de comunicación para "hacer amigos nativos", "para afrontar el clima", el manejo dedistancia social y cuando "tratan con alguien desagradable o malhumorado". Por su parte, los vascos encontraron más dificultades interpersonales al "acudir a lugares de culto religioso", "tratar con la burocracia" e "ir al médico", y "al relacionarse con personas del otro sexo" (distancia social) (véase Tabla 2).

Con el paso del tiempo (medida actual), los brasileños indicaron más dificultades interpersonales y de comunicación para "hacer amigos nativos", "hacerse entender", "entender el sentido del humor" y "afrontar el clima". Por su parte, los vascos señalaron más dificultades para "acostumbrarse a la comida local" y "tratar con la burocracia" (véase Tabla 2). Se mostraron tres efectos de interacción en función del grupo y el tiempo de estancia en el país de acogida. Los dos primeros corresponden a las relaciones interpersonales (comprender el idioma y acudir al médico) y el tercero, al manejo de la distancia social (trato con personas que miran fijamente) (véase Tabla 2) (Hip. 2).

\section{TABLA 2}

Escala de adaptación socio cultura: items con diferencias significativas entre los dos grupos de inmigrante

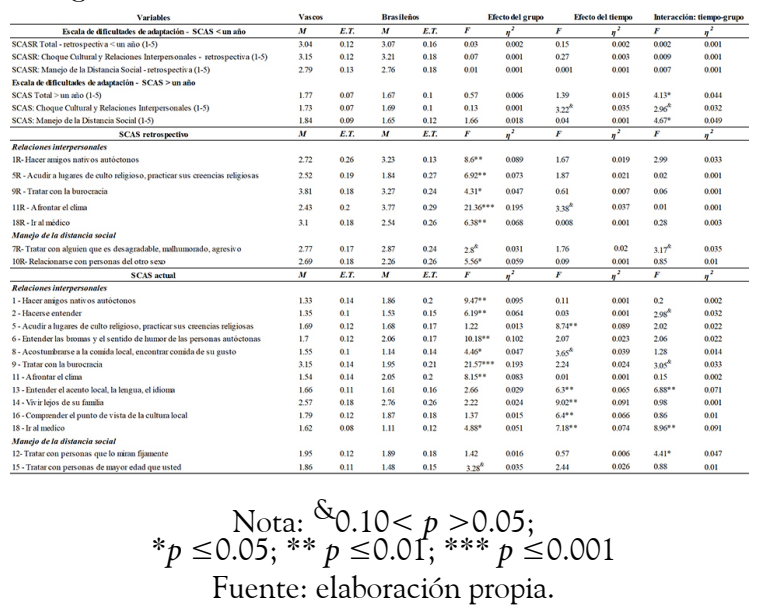

| Universitas Psychologica | V. i6 | No.5 | 2017 | 
El primer efecto muestra que los vascos que llevaban menos de 7 años residiendo en Brasil indicaron más dificultad para entender el acento local y la lengua que los que llevaban más, y entre los brasileños no hubo diferencias estadísticamente significativas (véase Figura 1). Esto es, los vascos que llegaron más recientemente a Brasil son los que indicaron tener más dificultades de comprensión de la lengua y el acento local (véase Tabla 2).

\section{Figura 1}

SCAS (13) Entender el acento y el idioma local

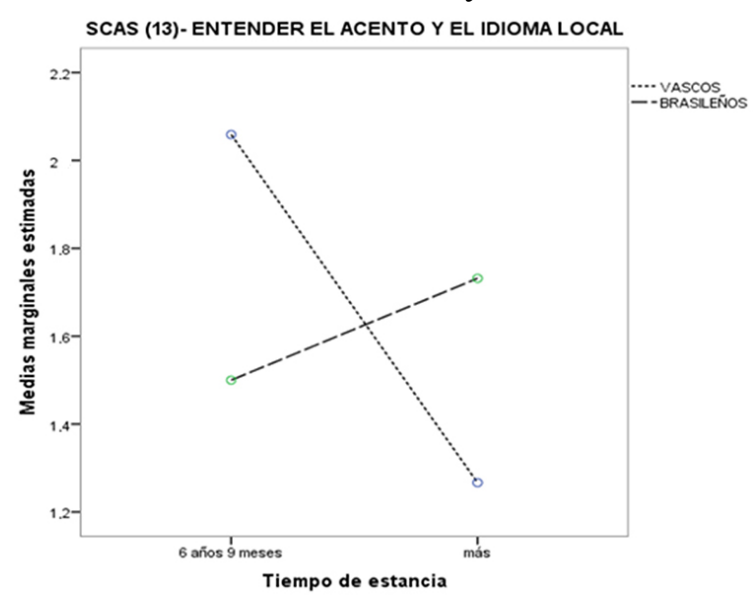

Fuente: elaboración propia.

El segundo efecto de interacción indicó que los vascos recién instalados presentaron más dificultades en acudir al médico $(M=1.94, D T$ $=0.13)$ que los que llevaban más tiempo $(\mathrm{M}=$ $1.3, \mathrm{DT}=0.09, t=3.89, p<0.001)$, mientras que para los brasileños este aspecto era poco relevante, tanto para los que llevaban menos de 7 años como para los que llevaban más tiempo residiendo en el País Vasco $(M=1, D T=0.22$ vs $M=1.22, D T=0.08, t=-0.93, p=0.48$ ).

"Tratar con personas que lo miran fijamente" fue el tercer efecto de interacción significativo (véase Figura 2). De modo que los vascos que llevaban menos de 7 años de residencia y los brasileños con más de 7 años percibieron más dificultad al "tratar con personas autóctonas que los miren fijamente" ( $M=2.18, D T=0.19$ vs $M=2.12$, $D T=0.12)$. Este patrón inverso indica que para los vascos que llevaban hasta una media de siete años residiendo en el país de acogida y para los brasileños de larga estancia, este aspecto era más saliente, aunque hay que recordar que las puntuaciones fueron bajas, menores de 2 en un rango de 1 a 5 (véase Tabla 2).

\section{Figura 2}

SCAS (12) Tratar con personas que lo miran fijamente

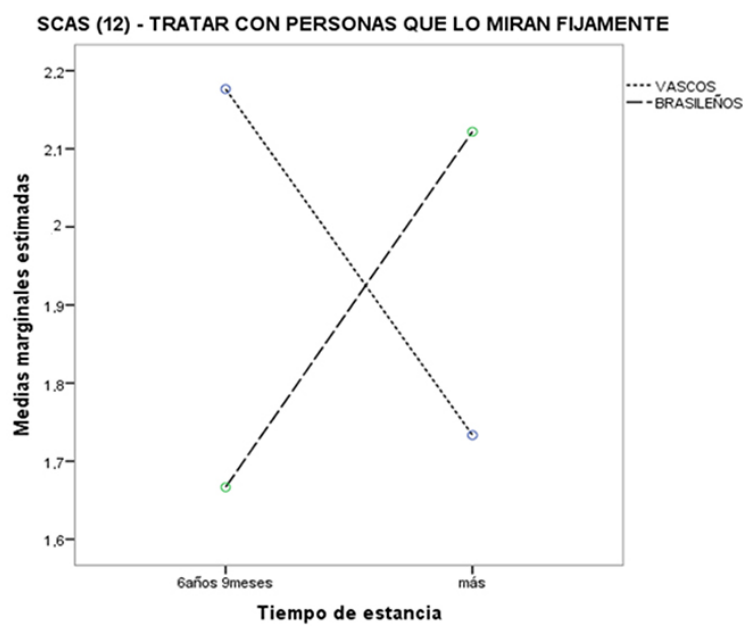

Fuente: elaboración propia.

Prácticas culturales: sociedad de acogida

Los dos grupos de inmigrantes mostraron altas puntuaciones en las prácticas culturales de la sociedad de acogida (puntuaciones alrededor de 4 en una escala de 1 a 5, Hip.3). Se encontró un efecto de interacción grupo por tiempo de estancia (véase Figura 3), de manera que los brasileños adoptaban más las prácticas de la sociedad de acogida en las primeras etapas (hasta los siete años de estancia) que cuando llevaban más tiempo $(M=4.13, D T=0.2$ vs $M=3.86$, $D T=0.07)$, mientras que sucedía lo contrario en el caso de los vascos que asimilaban más las prácticas culturales brasileñas cuando llevaban más años residiendo en Brasil que en las primeras etapas $(M=4.07, D T=0.09$ vs $M=3.76, D T$ $=0.12$ ). 


\section{Figura 3}

Prácticas culturales de la sociedad de acogida según tiempo de estancia y grupo

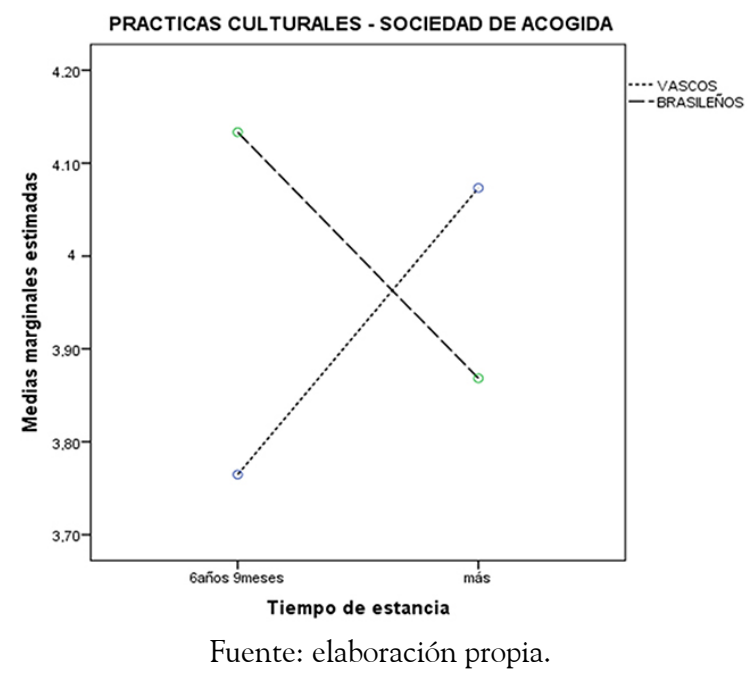

Prácticas culturales: sociedad de origen

Tanto los vascos como los brasileños mantenían sus prácticas culturales de origen con una intensidad media, no hubo cambios significativos con relación al tiempo de residencia, ni efectos de interacción. En ambos grupos las prácticas de la sociedad de acogida $(\mathrm{M}=3.93$, $\mathrm{DT}=0.5)$ eran más intensas que las practicas de origen $(\mathrm{M}$ $=2.76, \mathrm{DT}=0.59 ; t(93)=15.12, p<0.001)$ (Hip.3).

Actitudes y estrategias de aculturación: sociedad de acogida y sociedad de origen

Tanto los vascos como los brasileños expresaron el deseo de mantener las costumbres del país de acogida y de origen (puntuaciones alrededor de 3 en una escala de 1 a 5), donde los vascos estaban ligeramente más orientados hacia la sociedad de acogida y los brasileños hacia la de origen (efecto principal $p<0.001$ ). Por otra parte, las actitudes positivas hacia la sociedad de acogida se incrementaron con el tiempo de estancia (efecto directo del tiempo). Hubo un efecto de interacción (véase Figura 4), con un patrón inverso donde los vascos que llevaban poco tiempo estaban fuertemente ligados al origen $(M$ $=4.22, \mathrm{DT}=0.19)$, y con el tiempo disminuía esta actitud $(M=3.75, D T=0.15)$; por su parte los brasileños con el tiempo se orientaban más hacia sus orígenes $(M=2.33, D T=0.33$ vs. $M$ $=3.29, D T=0.12)($ diferencias $p<0.05)$.

\section{Figura 4}

Actitudes hacia la sociedad de origen según tiempo de estancia y grupo

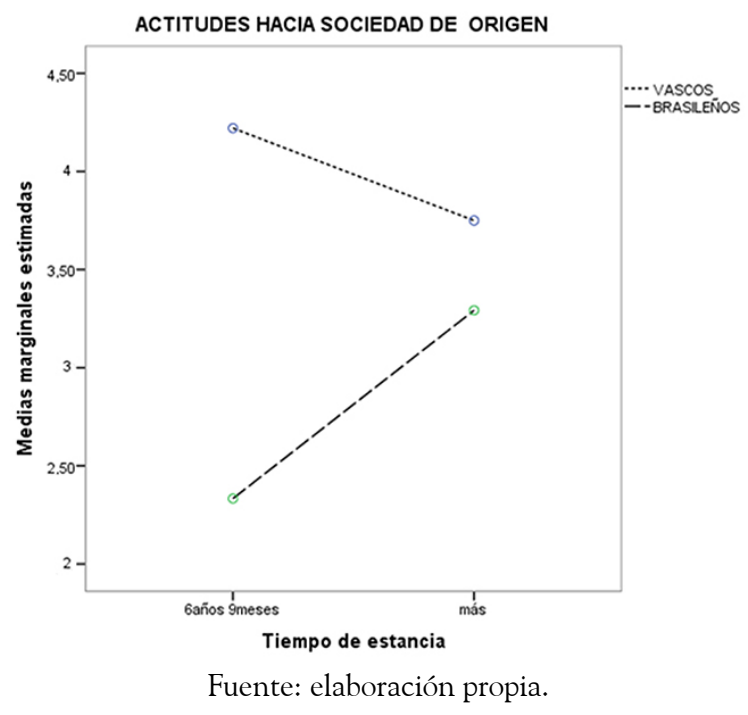

\section{Discusión}

\section{Dificultades de adaptación}

$\mathrm{Al}$ analizar el choque cultural entre dos grupos inmigrantes, se constata que las dificultades globales de adaptación son similares entre vascos y brasileños durante el primer año de estancia en el país de acogida. Las dificultades de adaptación son altas en casi todas las esferas, en donde predominan las relativas a la dimensión de manejo de las Relaciones interpersonales, con el paso del tiempo el choque disminuye, y adquiere más importancia la dimensión de Manejo de la distancia social, especialmente en el caso de los vascos. Asimismo, los vascos recién instalados en Brasil presentan más dificultades que los veteranos y que los brasileños, especialmente con el "Manejo de la distancia social" y, en menor medida, con las "Relaciones interpersonales". Por 
su parte los brasileños señalan pocas diferencias, sean veteranos o recién llegados.

Del conjunto de ítems que componen la Escala de Dificultades Socioculturales de Adaptación (SCAS), se han encontrado diferencias en función del grupo, tiempo de estancia en el país de acogida y la interacción entre ambos, en 7 de los 19 ítems de la escala cuando se menciona el primer año de estancia. En la medida relativa al momento actual, se mostraron diferencias en la mayoría de los ítems (13/19), lo que indica que con el tiempo la experiencia de choque cultural se transforma en más heterogénea. Así, con el paso del tiempo, se produce una adaptación al nuevo medio, como también mostraron estudios precedentes (Basabe et al., 2009; de Luca et al., 2011; LaFromboise et al., 1993; Ward \& Kennedy, 1999).

\section{Dificultades de adaptación: Relaciones} interpersonales y Comunicación

$\mathrm{Al}$ inicio de la experiencia migratoria, respecto a las "Relaciones interpersonales" los brasileños manifestaron mayor dificultad para afrontar el clima en comparación con los vascos, quienes mostraron mayor dificultad en el trato con la burocracia.

Considerando que el clima constituye un elemento que marca diferencias entre Brasil y España, y que en ambos países la climatología es muy variada de unas regiones a otras, en la región de origen inmigratoria de la totalidad de los brasileños y destino de los inmigrantes vascos de este estudio, predomina el clima tropical atlántico, caracterizado por ser caliente y húmedo la mayor parte del tiempo, situación que contrasta con las características climáticas de la provincia de Álava, en la cual predomina el clima mediterráneo continental, con cálidos y secos veranos y fríos y nevados inviernos. En este sentido, puede suponerse que resulte más fácil acostumbrarse al clima de São Paulo. En esta misma línea, el estudio de Ángel (2007) encontró que a los inmigrantes extranjeros procedentes de países colectivistas, les costaba adaptarse al clima y al ritmo de vida más que los estudiantes, viajeros o trabajadores vascos expatriados.

El trato con la burocracia durante el primero año de estancia en Brasil, para los vascos significó una situación de gran dificultad que disminuyó poco con el paso del tiempo; mientras que para los brasileños el grado de dificultad fue disminuyendo conforme se incrementó el tiempo de estancia en España. Estas diferencias pueden relacionarse con las políticas migratorias de los dos países respecto a la legalización documental de residencia. Por lo general en España la nacionalidad para los latinos es una realidad después de dos años ininterrumpidos de residencia, en cuanto que en Brasil se exigen quince años sucesivos de residencia, excepto en determinados casos, como el de los inversores, que son suficientes cuatro años (da Silva Guimarães, 2002; Solé, Cavalcanti, \& Parella, 2011). Situación directamente relacionada con una de las características migratorias de esta muestra en particular, donde la mayor parte de los brasileños salió de su país con un contrato de trabajo que, con sus prórrogas, permitió a los trabajadores y sus familiares directos adquirir la nacionalidad española. De manera diferente, los vascos se dividen en dos grupos proporcionalmente equivalentes, los que han emigrado aventurándose, y los que han emigrado con un contrato de trabajo no superior a los 15 años, y decidieron quedarse.

Siguiendo con las fuentes de stress de aculturación, los vascos manifestaron mayores dificultades para acudir a lugares de culto religioso y practicar sus creencias religiosas al inicio comparados con los brasileños, y estas dificultades se diluyeron con el paso del tiempo para ambos colectivos. Varios son los factores que pueden explicar las diferencias en la percepción de dificultades para el culto religioso. Por una parte, el gran tamaño de las ciudades y barrios, además de la mayor diversidad religiosa de iglesias y creencias características de Brasil y de Sao Paulo, contrasta con el tamaño más pequeño y la mayor cercanía de los lugares de culto (iglesias) en el País Vasco. Otro aspecto que diferencia las prácticas religiosas en ambos países y que puede producir choque cultural para los 
vascos, puede ser el mayor sincretismo de las religiones en Brasil. Sincretismo religioso no siempre sencillo de comprender para las personas externas o novatas de la sociedad brasileña, que puede interpretarse más como una manifestación cultural que una práctica religiosa (Almeida \& Montero, 2000; Teixeira, 2005).

Respecto al acceso a los servicios médicos, los dos grupos de inmigrantes revelaron ciertos inconvenientes para acudir al médico en el país de acogida. No obstante, esta situación es destacada más por los vascos que por los brasileños, y en especial por los vascos recién instalados. Esto puede deberse al sistema de salud público vigente en los dos países y el acceso tanto del inmigrante como del autóctono al mismo. El sistema sanitario español cuenta con una estructura pública de atención ya estructurada. Sin embargo, la estructura sanitaria pública de Brasil viene presentando progresivos cambios en las últimas décadas (Asensi \& Pinheiro, 2013; Rico, Freire, \& Gérvas, 2007), pero resultan muy lentos para suplir su precariedad. Esta realidad proporciona mayor facilidad de acceso en la atención sanitaria pública para los brasileños residentes en España, mientras que los vascos residentes en Brasil tienen que hacer uso, en su mayoría, de seguros o centros privados.

$\mathrm{Al}$ inicio de experiencia migratoria, a ambos grupos les cuesta adaptarse a las costumbres culinarias, a los productos y su forma de preparación. Conforme pasa el tiempo, los vascos siguen destacando más dificultades que los brasileños. Hay que considerar que el País Vasco presenta una tradición gastronómica muy enraizada en su cultura, los habitantes nativos se enorgullecen de su gastronomía principalmente basada en los productos de su tierra (Haig, 2008; Morales, 2012). La gastronomía representa un punto muy fuerte en la socialización y una manera de reforzar la identidad étnica (Goicoechea, 1984). Por su parte, la gastronomía brasileña adquirió un aspecto más multicultural, con las diferentes costumbres culinarias aportadas por cada una de sus etnias (Girard, 2009; Klein, 1996; RomeroValiente, 2013). En este sentido, aunque en los dos países actualmente es posible el acceso a variados productos gastronómicos, la fuerte identidad étnica y su relación con la gastronomía puede explicar esta mayor importancia que los vascos otorgan a la comida como fuente de choque cultural (Azurmendi, Bourhis, Ros, \& García, 1998).

Entender el idioma y el acento local no representa un fuerte inconveniente ni para los inmigrantes vascos ni para los inmigrantes brasileños. Sin embargo, las trayectorias de ambos grupos parecen divergir, dado que al principio de la estancia los vascos presentaron más dificultades en entender el idioma y el acento portugués, mientras que los brasileños percibieron más dificultades con el paso del tiempo en España. Estos contrastes pueden tener su origen en las distintas características con las cuales son percibidos estos colectivos culturales. En diversos estudios, se ha recalcado el aspecto alegre y extrovertido del brasileño (González \& Ubillos, 2011; Masanet-Ripoll \& Baeninger, 2010; Santiago \& Zubieta, 2006) y el predominio de unos rasgos más cerrados, serios, desconfiados y prudentes en los vascos (Sangrador, 1996; Techio, 2011; Zlobina et al., 2004). Esto puede corresponder, en parte, a que en los primeros años de residencia los vascos perciban más dificultad en la comprensión y habla del idioma portugués, por lo que eran más cautelosos a la hora de comunicarse, y con el paso del tiempo obtuvieron un dominio mayor y seguro del portugués. Por otra parte, los inmigrantes brasileños se arriesgan y se expresan más, elaboran una mezcla del castellano y portugués sin traducir o traducidos incorrectamente, el "portuñol". Esta mezcla que tiene como finalidad proporcionar una comunicación puntual cuando se transforma en un "idioma de uso frecuente", puede adquirir características prejudiciales por falta de dominio lingüístico del castellano en varias esferas de la vida cotidiana importantes para la integración en el nuevo contexto (Fernández García, 2006; Fernández García, 1988).

Para los dos grupos de este estudio, vivir lejos de la familia ha representado, especialmente en los comienzos de la experiencia migratoria, una dificultad considerable que fue disminuyendo su importancia a lo largo de los años. Este 
cambio puede considerarse parte del proceso de adaptación, de manera que el sentimiento de añoranza hacia la familia o a las personas cercanas que se quedaron en el país de origen va disminuyendo conforme el inmigrante adquiere mayor dominio de la cultura de acogida (Zlobina et al., 2004).

\section{Dificultades de adaptación: Manejo de la Distancia Social}

En relación con el Manejo de la Distancia Social, al principio conocer a personas desconocidas y "ser entrevistado para algo" eran aspectos representativos, y con los años de estancia pierden fuerza en los dos grupos. Durante el año de la llegada al país de acogida se destacaban las dificultades en el trato social; los brasileños resaltaban "el trato con personas autóctonas desagradables, malhumoradas y agresivas", mientras que los vascos indicaban las dificultades para relacionarse con personas nativas de otro sexo. Estas diferencias se diluyen con el tiempo de estancia. Otra fuente de choque se manifiesta en el malestar por "tratar con personas autóctonas que miran fijamente", por otra parte, los dos grupos han referido pocas dificultades en el trato con personas de mayor edad durante el primer año de estancia, así como en los posteriores, aunque esto ha sido más destacado en el caso de los vascos, a los que les resultaba algo más difícil el trato con personas autóctonas mayores.

Estas diferencias pueden ser explicadas por los estilos comunicativos de los dos países en cuestión. Comparativamente el País Vasco y España presentan una cultura más individualista (Hofstede, 2001), que se caracteriza por un estilo más explícito y directo, en el cual los puntos de vista son manifestados de forma clara y directa, lo que es percibido por las culturas más colectivistas, en el caso la brasileña, como una actitud grosera y agresiva, en la que se considera que estas culturas utilizan un estilo más implícito e indirecto, en el que la mayor parte de la información está en el contexto y no en la palabra, y donde las personas intentan evitar la confrontación y los desacuerdos (Gudykunst, Yoon, \& Nishida, 1987; Hall \& Hall, 1990; Trompenaars, 1994). Por su parte, los vascos han destacado dificultades en las relaciones en función de la edad (con las personas mayores) y el otro sexo. Estas diferencias pueden tener su origen, por una parte, en la mayor jerarquía y trato deferente para los mayores en la cultura brasileña, mientras que la mayor expresividad emocional de la cultura brasileña puede chocar con un estilo más controlado de las emociones y una segregación de género en las actividades de ocio en el País Vasco (Zlobina et al., 2004; Hofstede, 2001; Páez Fernández, Ubillos, \& Zubieta, 2003).

El choque en los brasileños se manifiesta en el Manejo de la distancia social, por el trato con personas malhumoradas y desagradables (Masanet-Ripoll \& Baeninger, 2010), lo cual puede relacionarse con la mayor percepción de discriminación entre los inmigrantes brasileños. Congruentemente con ello, la integración en la sociedad de acogida parece más resistente para los brasileños (que presentan más dificultades, para "hacer amigos nativos").

\section{Variables de aculturación}

Con respecto a la aculturación, el esfuerzo de adaptación es alto entre los inmigrantes, de manera que se realiza una intensa actividad para aprender las prácticas y costumbres locales, como manifiesta el hecho de que las puntuaciones en la intensidad de las prácticas de la sociedad de acogida sean mayores que las de origen. Los brasileños presentan una fuerte orientación hacia el país de acogida especialmente en los primeros tiempos y, por el contrario, los vascos recién llegados se mantienen más centrados en su grupo de origen, mientras que en los vascos veteranos pierden fuerza las prácticas culturales de origen. Por lo tanto, se constata que el tiempo de estancia afecta a las prácticas culturales de origen y acogida (Zlobina et al., 2004) pero esta relación es variable en función del grupo y la cultura.

Como es habitual en otros estudios (Basabe et al., 2009; Navas et al., 2004), los inmigrantes 
expresan actitudes biculturales. La mayoría de los vascos adoptan una estrategia bicultural (81\%), mientras que los brasileños se reparten entre la asimilación (34\%), la biculturalidad (29\%), y la separación (23\%), siendo la opción difusa o marginación minoritaria (12\%). Asimismo, las actitudes positivas hacia la sociedad de acogida se incrementan con el tiempo de estancia. Sin embargo, los vascos recién instalados están fuertemente ligados al origen y con el tiempo se vinculan a la sociedad de acogida, mientras que los brasileños veteranos se orientan más hacia sus orígenes que los recién instalados.

\section{Aportaciones y limitaciones del estudio}

Este estudio ha tratado de analizar, desde una óptica menos usual en las investigaciones de aculturación, el proceso de adaptación de dos grupos relativamente equiparables, vascos en Brasil y brasileños en el País Vasco. Uno de los inconvenientes de dicha comparación fue realizar una equiparación total por tiempo de estancia medio en el país de acogida, debido a que la inmigración brasileña en el País Vasco es relativamente reciente, en tanto que la diáspora vasca en Brasil tiene una larga historia.

Asimismo, la naturaleza retrospectiva del estudio es una limitación para el análisis evolutivo de la adaptación a lo largo del tiempo de las primeras generaciones de inmigrantes. Se precisan estudios longitudinales, por un lado, y por otro, estudios de las sucesivas generaciones de hijos y nietos de inmigrantes, que permitan analizar los cambios en la enculturación a lo largo del tiempo.

Finalmente, y a pesar de que el contraste entre estos dos grupos migrantes permitió mostrar las diferencias y similitudes del choque cultural en función del tiempo de estancia, de la cultura de origen y de la sociedad receptora, es importante considerar que dadas las limitaciones en relación a la validez externa, los resultados no se pueden generalizar a toda la inmigración en Brasil y País Vasco, por lo tanto sería necesario mejorar este aspecto ampliando el estudio a muestras más amplias, en distintos contextos y estratos sociales en los dos países.

\section{Agradecimientos}

Agradecemos a las personas vascas y brasileñas, que gentilmente aportaron sus experiencias como inmigrantes, al Centro Vasco Eusko Alkartasuna de São Paulo pela acogida e interés y a las personas que directa o indirectamente contribuyeron con su saber para la realización y concreción de este estudio.

\section{Referencias}

Ángel, O. (2007). Diferencias culturales y choque cultural: adaptación socio-cultural de migrantes (Suficiencia Investigadora no publicada). Universidad del País vasco, Donostia-San Sebastián.

Almeida, R. M., \& Montero, P. (2000). O campo religioso brasileiro no limiar do século: Problemas e perspectivas. En H. Rattner (Ed.), Brasil no limiar do século XXI (pp. 325-339). São Paulo: EDUSP.

Asensi, F. D., \& Pinheiro, R. (2013). Indo além da judicialização: $O$ Ministério Público e o direito à saúde. Confluências. Revista Interdisciplinar de Sociologia e Direito, 11(2), 27-68.

Azurmendi, M. J., Bourhis, R. Y., Ros, M., \& García, I. (1998). Identidad etnolingüística y construcción de ciudadanía en las Comunidades Autónomas Bilingües (CAB) de España. Revista de Psicología Social, 13(3), 559-589.

Basabe, N., Páez, D., Aierdi, X., \& JiménezAristizabal, A. (2009). Calidad de vida, Bienestar subjetivo y Salud: inmigrantes en la CAPV. Zumaia: Observatorio Vasco de Inmigración de Ikuspegi.

Bochner, S. (2003). Culture shock due to contact with unfamiliar cultures. En W. J. Lonner, D. L. Dinnel, S. A. Hayes, \& D. N. Sattler (Eds.), Online Readings in Psychology and Culture (Unit 8, Chapter 7). Washington, DC: Center for Cross- 
Cultural Research, Western Washington University, Bellingham. Recuperado de htt p://www.edu/ culture

Chun, K. M., Organista, P. B., \& Marín, G. (Eds.). (2003). Acculturation. Advances in theory, measurement, and applied research. Washington, DC: APA.

da Silva Guimarães, F. X. (2002). Nacionalidade: aquisição, perda e reaquisição. São Paulo: Editora Forense.

de Luca, S., Bobowik, M., \& Basabe, N. (2011). Adaptación sociocultural de inmigrantes brasileños en el País Vasco: Bienestar y aculturación. Revista de Psicología Social, 26(2), 275-294.

Fernández García, M. J. (2006). Portuñol y literatura. Revista de estudios extremeños, $62(2), 555-577$.

Fernández García, M. J. (1988). ¿Qué es el Portuñol?. Letras, Badajos: Universidad de Extremadura. Recuperado de http://www.dip-badajoz.es/cultura/ceex/ reex_digital/reex_LXII/2006/T.\%20LXII\% 20n. $\% 202 \% 202006 \% 20$ mayo-ag/RV00081 8.pdf

Furnham, A., \& Bochner, S. (1982). Social difficulty in a foreign culture: An empirical analysis. En S. Bochner (Ed.), Cultures in contact: Studies in cross-cultural interaction (pp. 161-198). Oxford: Pergamon.

Girard, L. L. (2009). A inserção de imigrantes europeus na cidade de Brasília. Net Saber: Artigos: A imigração no Brasil. Recuperado de http://artigos.netsaber.com.br/resumo_a rtigo_15951/artigo_sobre_a_imigra\%C3\% 87\% $3 \%$ 33o_no_brasil

Gives, M. (2013). Emigración española contemporánea. Pasto, Colombia: Universidad de Nariño. Recuperado de http://ceilat.udenar.edu.co/wp-content/ uploads/2014/05/EMIGRACION_ESPA\% C3\%91OLA_CONTEMPORANEA.pdf

Goicoechea, E. R. (1984). Cuadrillas en el País Vasco: Identidad local y revitalización étnica. REIS Revista Española de Investigaciones Sociológicas, 25, 213-222.

González-Castro, J. L., \& Ubillos, S. (2011). Estereotipos de la inmigración en España:
Influencia de los agentes de socialización de masas. En E. M. Techio. (Ed.), Cultura e produção das diferenças: Estereótipos e preconceito no Brasil, Espanha e Portugal (pp.173-214). Brasilia: TechoPolitik.

Gudykunst, W. B., Yoon, Y. C., \& Nishida, T. (1987). The influence of individualism-collectivism on perception of communication in in-group and out-group relationships. Communication Monographs, 54(3), 296-306.

Haig, N. (2008). Inaugurado Sukal Leku, el primer centro vasco de innovación, desarrollo e investigación gastronómica. Sustrai: revista agropesquera, 83, 12-13.

Hall, E. T., \& Hall, M. R. (1990). Understanding cultural differences (Vol. 12). Yarmouth, ME: Intercultural press.

Hofstede, G. (2001). Culture's consequences: Comparison values, behaviours institutions and organizations across nations. Thousand Oaks, CA: Sage.

Klein, H. S. (1996). La inmigración española en Brasil: (siglos XIX y XX). Asturias: Colombres.

LaFromboise, T., Coleman, H. L. K., \& Gerton, J. (1993). Psychological Impact of Biculturalism: Evidence and Theory. Psychological Bulletin, 114(3), 395-412.

Masanet-Ripoll, E., \& Baeninger, R. (2010). Imágenes recíprocas y estereotipos entre la población brasileña y autóctona en el contexto multicultural español. Convergencia, 17(53), 151-175.

Masanet. E. R, \& Padilla, B. (2010). La inmigración brasileña en Portugal y España: ¿Sistema migratorio ibérico? OBETS. Revista de Ciencias Sociales, 5(1), 49-86.

Moghaddam, F. M., Taylor, D. M., \& Wright, S. C. (1993). Social psychology: A crosscultural perspective. Nueva York, NY: W. H. Freeman.

Ministério das Relações Exteriores do Brasil. (2013). Estimativas populacionais das comunidades brasileiras no Mundo. Recuperado de http://www.brasileirosnomu ndo.itamaraty.gov.br/a-comunidade/estima tivas-populacionais-das-comunidades/ 
Morales, J. C. (2012). Euskadi, referente mundial del turismo enogastronómico. Recuperado de http://actualidadgastronomica.es/Euska di-referente-mundial-del-turismo-enogastr onomico/

Navas, M., Pumares, P., Sánchez, J., García, M. C., Rojas, A., Cuadrado, I., Asensio, M., \& Fernández, J.S. (2004). Estrategias y actitudes de aculturación: la perspectiva de los inmigrantes y de los autóctonos en Almería. Sevilla: DGCPM, Junta de Andalucía.

Páez, D., Fernández, I., Ubillos, S., \& Zubieta, E. (2003) (Eds.). Psicología social, Cultura y Educación. Madrid: Prentice-Hall.

PERE. (2014). Estadística del Padrón de Españoles residentes en el extranjero a 1 de enero de 2014. Recuperado de http://www.ine.es/prensa/n p833.pdf.

Rico, A., Freire, J. M., \& Gérvas, J. (2007). El sistema sanitario español (1976-2006): Factores de éxito en perspectiva internacional comparada. En A. Espina (Ed.), Estado de bienestar y competitividad: la experiencia europea (pp. 401-444). Madrid: Fundación Carolina.

Romero-Valiente, J. M. (2013). La migración española a Brasil (fines del siglo XIXactualidad): Magnitudes y evolución. En Universidad de Huelva (Ed.), Migraciones iberoamericanas. Las migraciones, EspañaBrasil (pp. 33-58). Huelva: Centro de Investigación en Migraciones. Universidad de Huelva/LABIMI.

Sabatier, C., \& Berry, J. W. (1996). Inmigración y aculturación. En R. Bourhis \& J.P. Leyens (Eds.), Estereotipos, discriminación y relaciones entre grupos (pp. 217-240). Madrid: McGraw Hill.

Sangrador, G. J. L. (1996). Identidades, actitudes y estereotipos en la España de las autonomías (resultados del estudio 2123). Madrid: Centro de Investigaciones Sociológicas (CIS).

Santiago, G. A., \& Zubieta, I. J. C. (2006). Resultados Globales. En G.A. Santiago, \& I.J.C. Zubieta (Eds.), Los estereotipos nacionales de las poblaciones
Del MERCOSUL y España (pp. 268-303). Santander: T.G.D.

Solé, C., Cavalcanti, L., \& Parella, S. (2011). La inmigración brasileña en la estructura socioeconómica de España. Madrid: Grafo.

Smith, P. B., \& Bond, M. H. (1999). Social Psychology across cultures. London: Prentice Hall.

Techio, E. M. (2011). Estereótipos sociais como preditores das relações intergrupais. En E. M. Techio \& M. E. Oliveira Lima (Eds.), Cultura e produção das diferenças: Estereótipos e preconceito no Brasil, Espanha e Portugal (pp. 21-75). Brasilia: TechoPolitik.

Teixeira, F. (2005). Faces do catolicismo brasileiro contemporâneo. Revista Usp, 67, 14-23.

Trompenaars, F. (1994). Riding the waves of culture. Understanding cultural diversity in business. London: Nicholas Brealey Pub.

Ward, C. (1996). Acculturation. En D. Landis \& R. Bhagat (Eds.), Handbook of intercultural training (pp. 124-147). Thousand Oaks, CA: Sage.

Ward, C., \& Kennedy, A. (1999). The measurement of sociocultural adaptation. International Journal of Intercultural Relations, 23(4), 659-678.

Ward, C., Bochner, S., \& Furnham, A. (2001). The psychology of Culture Chock. East Sussex: Routledge.

Zlobina, A., Basabe, N., \& Páez, D. (2004). Adaptación de los inmigrantes extranjeros en España: superando el choque cultural. Revista Migraciones, 15, 43-84.

\section{Notas}

* Artículo de investigación. 